\title{
Erratum to: Atomically thin two-dimensional materials for functional electrodes of electrochemical devices
}

\section{A review}

\section{Serge Zhuiykov $\cdot$ Eugene Kats}

Published online: 10 March 2013

(C) Springer-Verlag Berlin Heidelberg 2013

\section{Erratum to: Ionics}

\section{DOI 10.1007/s11581-012-0837-2}

Figures 24 and 25 reprinted from Balendhran S. et al. [184] with permission from Wiley. Table 1 Properties of graphene and other carbon allotropes [19]. Table 2 reprinted from Nico C. et al. [205] with permission from the American Chemical Society. Fig. 3 reprinted from Bronson et al. [44] with permission from The Royal Society of Chemistry. Fig. 4 reprinted from $\mathrm{Wu}$ et al. [19] with permission from Elsevier Science. Fig. 32 reprinted from Le Viet et al. [203] with permission from The American Chemical Society.

The online version of the original article can be found at http://dx.doi.org/ 10.1007/s11581-012-0837-2.

S. Zhuiykov $(\bowtie) \cdot$ E. Kats

CSIRO, Materials Science and Engineering Division,

37 Graham Road,

Highett, Victoria 3190, Australia

e-mail: serge.zhuiykov@csiro.au 